\title{
CONTROL Y GALIDAD DE LA LEY. ANÁLISIS DE LOS MECANISMOS DE GONTROL DE LA GALIDAD LEGISLATIVA Y SU APLICACIÓN EN COLOMBIA*
}

\author{
CONTROL AND QUALITY OF LEGISLATIVE PRODUCTS. ANALYSIS \\ TO THE CONTROL MECHANISMS OF THE LEGISLATIVE \\ PRODUCTS QUALITY AND THEIR APPLICATION IN COLOMBIA
}

\author{
Yenny Andrea Celemín CaICEdo** \\ Édgar Hernán Fuentes-CONTRERAS***
}

RESUMEN: El artículo identifica la deficiencia de los productos legislativos como una de las principales manifestaciones de la llamada crisis de la representación política. A
ABSTRACT: The article identifies legislative products problems as one of the main manifestations of the so-called political representation crisis. Based on an analysis of the limited attention on the part of the

* Recibido el 6 de enero de 2020; aprobado el 12 de octubre de 2020. Artículo de investigación que expone los resultados preliminares de los proyectos de investigación: "Pesos y contrapesos y calidad de la legislación", vinculado con el grupo de investigación de Derecho Público de la Universidad de los Andes (Colombia) y "Ecos de la Historia" adscrito al grupo "Derecho y Globalización” de la Universidad de Bogotá Jorge Tadeo Lozano (Colombia); asimismo, toma resultados parciales de la investigación posdoctoral de uno de los coautores, que adelanta, como becario, en la Universidad de los Andes, Chile.

** ORCID: 0000-0003-0540-2036. Doctora en Derecho de la Universidad de los Andes (Colombia); abogada y magister en Derecho de la Universidad Nacional de Colombia; profesora asistente de la Facultad de Derecho de la Universidad de los Andes (Colombia) y fundadora del Instituto Internacional de Derechos Humanos, Colombia. Correo electrónico:ya.celemin24@uniandes.edu.co.

*** ORCID: 0000-0002-1066-0999. Doctor en Derecho, con mención internacional, y máster en Derecho Constitucional de la Universidad de Sevilla (España); magíster en Derecho de la Universidad Nacional de Colombia; especialista en Derecho constitucional de la Universidad Externado de Colombia y abogado de la Universidad de Antioquia (Colombia); actualmente desarrolla sus estudios posdoctorales en la Universidad de los Andes, Chile y se desempeña como el director del Área de Derecho Público de la Universidad de Bogotá Jorge Tadeo Lozano (Colombia).Correo electrónico: edgarfuentes@utadeo.edu.co; edherfucon@gmail.com.

Boletín Mexicano de Derecho Comparado, nueva serie, año LIII, núm. 158, mayo-agosto de 2020, pp. 579-618. 
partir de un análisis sobre la escasa atención por parte de la literatura académica frente a esta problemática, el trabajo realiza una revisión de algunos de los mecanismos de control existentes en el diseño institucional colombiano para el examen de la calidad de los productos legislativos. Así, en este trabajo se argumenta que estos mecanismos de control son insuficientes para evaluar la racionalidad y la calidad de las medidas adoptadas por el legislador en la solución de los problemas sociales, mientras que tampoco contribuyen a reducir la discrecionalidad en las posibilidades de adopción de decisiones por parte del órgano legislativo. En tres acápites, iniciando con una metodología explorativa respecto a las temáticas de calidad legislativa y los mecanismos de control de ésta, y después una recolección de la normativa colombiana, incluyendo las respectivas providencias judiciales de la Corte Constitucional, dará una visión crítica sobre la temática abordada y valorará la necesidad la adopción de mecanismos alternativos para sustentar el valor de la legislación nacional.

Palabras clave: democracia representativa, producto legislativo, calidad y racionalidad legislativa, control horizontal y vertical de los productos legislativos. academic literature regarding this problem, the work makes a review of some of the control mechanisms in the Colombian institutional design for the examination of the quality of legislative products. This work argues that the control mechanisms of legislation are not enough to assess the rationality and quality of the measures used by the legislator in the solution of social problems, neither do they reduce discretion in the possibilities of decision-making by legislators. In three parts, which includes an exploratory methodology regarding the issues of legislative quality and its control mechanisms, and also a set of Colombian statutes and judicial decisions of the $\mathrm{Co}^{-}$ lombian Constitutional Court on the matter, the article provides a critic of the issue and it begins some reflections about alternative mechanisms to support the value of national legislation.

Keyzerds: representative democracy, legislative product, legislative quality and rationality, horizontal and vertical control of legislative products.

\section{SUMARIO: I. Introducción. II. Abordajes teóricos para enfrentar el problema de la calidad de la ley. III. Mecanismos de control de la ley: ¿cómo controlar la calidad de la legislación? IV. La calidad ¿adjetivo predicable de los mecanismos para controlar la calidad de la legislación? V. Conclusiones. VI. Bibliografia.}

\section{INTRODUCGIÓN}

Una de las transformaciones más importantes en relación con el concepto de democracia está conectada con una creciente, y cada vez más común, tendencia ciudadana a la antipatía frente a los ideales normativos que dicho concepto encarna. A partir de este cambio, la concepción tradicional

Esta obra está bajo una Licencia Creative Commons

Atribución-NoComercial-SinDerivar 4.0 Internacional, IIJ-UNAM.

Boletín Mexicano de Derecho Comparado, núm. 158, mayo-agosto de 2020, pp. 579-618. 
de la democracia representativa, como fuente de legitimidad del poder político, está seriamente cuestionada.

Dicha animosidad a las capacidades de la democracia para permitir el autogobierno de la ciudadanía ha sido calificada como el síntoma más agudo del "síndrome de la fatiga democrática" (Van Reybrouck 2017, 17), "hastío de la democracia" (Rubio Carracedo 2000; Vallejo 2018) y de aquello denominado como "pérdida de centralidad de la representación política" (Criado 2018, 81).

Infortunadamente, la pérdida de confianza en la democracia representativa no es el único problema que esta forma de toma de decisiones y de cursos de acción social ha venido enfrentando. Otras complicaciones, igualmente graves, empiezan a ser identificadas desde la teoría de la democracia. Dentro de estos están las dificultades que vienen sufriendo las leyes como productos del proceso de representación política y como mecanismo primario de coordinación social. Entre los factores que han venido produciendo estos inconvenientes para las leyes están, según los autores (Centenera 2012; Gascón 2006; Rubio Llorente 2006):

La proliferación o inflación normativa, antinomias, redundancias, estratificaciones, abrogaciones innominadas, faltas de mínima coordinación normativa, inorgánica regulación de áreas del quehacer jurídico, hipostenia legislativa (un marcado déficit en los grados de eficacia de las normas, lo que trae aparejado un debilitamiento y desconfianza respecto a la legislación como marco de solución de los conflictos sociales) y ausencia de un marco ético justificatorio de su obligatoriedad. Dichos males generan graves problemas legislativos y prácticos que debilitan la autoridad de la ley, perjudicando, además, la labor de quienes son llamados a interpretar y aplicar dichas normas, como también a los ciudadanos destinatarios de las leyes (Pineda 2009, 139).

Del consenso que ha identificado los factores constitutivos de los problemas de la ley o del impacto de este fenómeno en la crisis de la representación, sin embargo, no se sigue la existencia de una amplia gama de recomendaciones en busca de soluciones a estas problemáticas. Por el contrario, el material disponible sobre este tipo de asuntos es más bien escaso, además de que suele tener un lugar más bien marginal en la enseñanza del derecho (Centenera 2016).

Así, es bastante común que estos temas ni siquiera aparezcan dentro del pensum o los programas de formación legal de las universidades, por 
lo menos, en Colombia. Ahora, si la atención hacia las soluciones a los problemas de la calidad de la legislación es escasa, mucho menos frecuente es la existencia de un análisis acerca de los mecanismos de control que disponen las Constituciones para asegurar que este tipo de problemáticas de la legislación no se presenten.

Con el propósito, entonces, de reflexionar sobre el tipo de mecanismos de control de la calidad de la legislación ${ }^{1}$ el objetivo de este texto es el de realizar un examen preliminar al funcionamiento del control constitucional como mecanismo del control de la calidad legislativa. Este examen será efectuado en el marco de una revisión general de los tipos de mecanismo de control a la calidad de la legislación reconocidos en el sistema jurídico colombiano. Por la naturaleza explorativa del artículo y como resultado preliminar de investigación, este estudio dará cuenta sucinta de los controles existentes en el ordenamiento jurídico colombiano actual para tal fin, pero dando prevalencia en el análisis a los controles que adelanta la Corte Constitucional colombiana. El análisis crítico de estas decisiones nos va a permitir sostener, como hipótesis de este artículo, que los mecanismos de control contemplados en Colombia son insuficientes o demasiado deficientes en sus propósitos de evaluar la racionalidad y la calidad de las medidas adoptadas por el legislador para la solución de los problemas sociales. Estos mecanismos tampoco contribuyen a reducir la discrecionalidad en las posibilidades de adopción de decisiones por parte del órgano legislativo.

Para fundamentar esta hipótesis, el artículo tendrá la siguiente división: en una primera parte se realiza una breve descripción de las propuestas y recomendaciones para solucionar los problemas de calidad de la legislación de acuerdo con la literatura comparada sobre la materia;

1 Pese a la diversidad de nociones y dimensiones que se involucran en el concepto de "calidad de la legislación", el actual texto asume que esta se desarrolla o mide, en buena parte, por la estabilidad normativa, en sentido jurídico, que debe derivarse de su coherencia con el ordenamiento jurídico al cual pertenece; de ahí que se de prevalencia a la técnica de redacción para el cumplimiento de los fines, que exista el acatamiento de los criterios para pertenecer al sistema jurídico y que, asimismo, sea acreedora de expresiones lingüísticas que direccione una prescripción completa, clara, suficiente para la sociedad. Dicho concepto será acompañado por la idea de racionalidad de ley, el cual será explicado siguiente al profesor Manuel Atienza (1997). Si bien, como será explicado, existe también una dimensión política, incluso una dimensión moral, sobre la calidad de la ley, estos no serán objeto central, a lo sumo coyuntural, del trabajo (cfr. Centenera 2015). 
para enseguida establecer los mecanismos de control de la calidad de la legislación en el constitucionalismo contemporáneo, para, previo a las conclusiones, analizar y explicitar el funcionamiento de algunos de estos mecanismos en el contexto colombiano. Así las cosas, empleado una metodología explorativa respecto a la doctrina tratante frente a la calidad legislativa y los mecanismos de control de ésta, se hará, además, una recolección normativa, incluyendo las sentencias de la Corte Constitucional, para alcanzar los objetivos señalados y los desarrollos propuestos.

\section{ABORDAJES TEÓRICOS PARA ENFRENTAR EL PROBLEMA DE LA GALIDAD DE LA LEY}

Sin duda, el concepto de democracia constitucional puede calificarse como la estructura que de manera dominante caracteriza la conformación de los Estados contemporáneos. Sin embargo, este concepto se ha venido explicando casi exclusivamente a partir de descripciones de las labores y rol de los tribunales en defensa de la supremacía de la Constitución, en general, y, en particular, de los derechos fundamentales. En contraste, no se ha brindado la misma atención a las tareas de los restantes poderes públicos; al final, "Los juristas y académicos solo se ocupan de jueces y tribunales" (Bar-Siman-Tov 2019, 539).

Dicha situación no es diferente en el contexto colombiano, donde tanto la doctrina como la educación y formación legal han dejado en la penumbra del campo jurídico el quehacer de democrático de órganos como la propia rama legislativa (Celemín 2016).

Frente a dicha desatención, las explicaciones que se han elaborado pueden concretarse en las palabras Imer Flores $(2005,45)$ así:

Déjenme señalar que, hasta ahora, el punto de vista dominante, ve a la legislación como un proceso que ha sido representado como político y no legal, y a la legislación como un producto (del proceso político) que ha sido descrito sobre todo como político, pero también como pre-legal, aún no es derecho hasta que la autoridad legal o el oficial pertinente diga que es derecho. Este hueco abierto al menos por la puerta de atrás por un análisis minimalista desde el punto de vista legal de los estatutos como un resultado especifico de la legislación ha dejado la actividad que lo originó largamente inexplorada. 
De acuerdo con este diagnóstico, lo relacionado con los productos legislativos ${ }^{2}$ y, específicamente, los problemas atenientes a la calidad de la legislación son ámbitos de reflexión que suelen estar por fuera del campo jurídico, según el punto de vista dominante en la academia jurídica. Dicha propensión de exclusión, también, puede ser sustentada en diversos argumentos, que no pueden estimarse como mutuamente excluyentes. El primero es la consideración a que las discusiones sobre la calidad legislativa pertenecen el ámbito de la política. ${ }^{3}$ Mientras, el segundo de ellos insiste en la idea de la validez como el centro de atención de la disciplina jurídica (y, así, haciendo más visible el legado más elocuente del formalismo jurídico). Este hecho remite el proceso de creación legal a la categoría de fenómeno anterior a las materias y a las problemáticas de las que usualmente se ocupa el derecho como disciplina. En otros términos, la expansión y protagonismo adquirido por el positivismo jurídico, y su afán de superar las aproximaciones al estudio del derecho propuestas desde el racionalismo iusnaturalista, contribuyeron a dejar por fuera del campo de análisis del derecho otra clase de consideraciones, especialmente aquellas que no estuvieran relacionadas con la revisión de las condiciones de validez de las normas jurídicas.

Este paradigma de ciencia jurídica aparece perfectamente sintetizado en la conocida clasificación de Austin entre ciencia de la legislación y jurisprudencia: la primera se identifica con una disciplina normativa cuyo objeto es conocer el "deber ser" del derecho, tarea que corresponde a los filósofos y a los políticos. La ciencia jurídica, como se le denomina en el ámbito continental, es en cambio, una disciplina descriptiva del derecho positivo y el auténtico feudo de los positivistas (Marcilla 2000, 99).

2 En el presente trabajo se entiende por "productos legislativos" a las denominadas leyes formales, es decir, aquellas normas que produce el órgano o Poder Legislativo, en desarrollo de la competencia constitucional legislativa, que cuenta con forma de ley y ha tenido que pasar por el procedimiento legislativo organizado por la normativa del ordenamiento jurídico. En consecuencia, se excluyen otras normas que puede dictar el legislador general y aquellas que producen los legisladores extraordinarios o excepcionales. Sobre el tema véase (Fuentes-Contreras 2018).

3 Bar-Siman-Tov $(2019,531)$ lo expresa para el contexto norteamericano diciendo: "En esta misma línea, hay explicaciones centradas en rasgos de la cultura jurídica tradicional estadounidense, que el derecho de creación jurisprudencial como fuente superior y auténtica del derecho, y contemplan la legislación como una fuente inferior, una fuente que sería más bien un asunto político, no tanto jurídico”. 
Además de estos elementos de índole teórica, los trabajos de Atienza han articulado explicaciones adicionales sobre esta desatención hacia los procesos y los productos provenientes del órgano de representación política. En efecto, para este autor, las características institucionales de las legislaturas amplifican la complejidad de los análisis sobre el trabajo o las decisiones que se toman por los cuerpos legislativos. Así, la responsabilidad política, la pluralidad y diversidad de los miembros del Parlamento, incluida la posibilidad que múltiples órganos cuenten con la iniciativa para impulsar la adopción de los proyectos legislativos, son rasgos que hacen más difícil la tarea de comprender el desenvolvimiento del razonamiento legislativo. Sobre este particular explica el profesor Atienza (2005, 300):

Para ponerlo brevemente, el discurso justificatorio ligado a la producción de las normas a través de las asambleas políticas es mucho más complejo que el que se realiza por los cuerpos judiciales. En orden de analizar la justificación hecha por un juez uno se puede enfocar y limitar al texto de la decisión, pero la decisión legislativa es normalmente menos estructurada. En otros términos, el razonamiento judicial tiene lugar entre estrictos límites que facilita su evaluación, pero esto usualmente no ocurre con el razonamiento legislativo. Por eso es por lo que los instrumentos producidos en las últimas décadas por la teoría del razonamiento legal no pueden ser usados con un significado simple para justificar el razonamiento legislativo.

A pesar de lo desalentador de este diagnóstico, como lo asevera Bar Siman Tov, el comienzo del siglo XXI se ha visto marcado por un resurgimiento de la legislación tanto en la enseñanza cómo en los estudios de teoría jurídica. Precisamente, el autor israelí ha explicado tal resurgimiento como una consecuencia directa de la crisis de la ley ${ }^{4}$ que se ha vivido en la mayor parte del siglo XIX y XX, donde se ha requerido fortalecer ámbitos y aspectos que contribuya a la solución de esta:

Parece que, en estos sistemas, una de las fuerzas impulsoras principales ha sido el aumento del número de leyes, que se ha visto acompañado por crecientes críticas sobre la mala calidad de la legislación. De ahí que, en Europa, la legisprudencia haya ganado terreno, en gran medida a resultas de un esfuerzo por mejorar la calidad (y en ocasiones también para reducir la

4 La crisis jurídica de la ley puede verse en: (de Cabo 2000; Laporta 1999; Tudela 2000-2001). 
cantidad de legislación). Y este esfuerzo, además, no ha provenido sólo de entornos académicos, sino también de gobiernos, organizaciones internacionales como la (UE y la OCDE) y organizaciones no gubernamentales, que han adoptado o promovido la adopción de programas de mejora legislativa y regulatoria (Bar-Siman Tov 2019, 548).

El conjunto de iniciativas para mejorar la calidad de la legislación tiene algunos puntos en común: el primero de estos es que ellas se centran en el producto legislativo y no prestan le mayor atención a los procedimientos de creación de la ley o a las interacciones de los legisladores entre sí y de los legisladores con otros actores en estos procesos. En segundo lugar, y por este motivo, tales iniciativas dirigen sus recomendaciones, preferiblemente, al grupo o el personal de apoyo legislativo, también conocidos como drafters, o las figuras técnicas y administrativas encargadas de cumplir las funciones de proyectar/conceptuar/hacer seguimiento a las iniciativas legislativas. Por consiguiente, estas recomendaciones están encaminadas a establecer una serie de preguntas o puntos de control que el diseñador legislativo debe seguir para lograr cierto grado de efectividad de la ley (Aitken 2013; Centenera 2012; Cormacain 2017; Karpen 2013; Niemivuo 2010).

Si bien debe reconocerse que el trabajo de este personal técnico es importante para lograr una legislación de calidad, no obstante, esta clase de enfoque pierde de vista un aspecto significativo: el tipo de controles que son necesarios sobre aquellos que tienen la responsabilidad directa de legislar, es decir, quiénes han sido elegidos electoralmente para cumplir con la función de creación normativa, que, por demás, no suelen contar con escenarios concretos de rendición de cuentas sobre la calidad de su labor. En ese ámbito, la ausencia de escenarios lo suficientemente significativos o fuertes en los que estas personas, como legisladores individualmente considerados o como miembros de una legislatura, se hagan responsables de las propuestas realizadas por ellos, termina minimizando la relevancia de su tarea y prescindiendo de su responsabilidad, inclusive, de la promulgación de una mala legislación.

Con esto no se indica que estos escenarios deban llegar a ser tan extremos cómo los que se practicaban en la democracia ateniense y que han sido rescatados por autores como John Elster en extractos como el siguiente: 
Since Ephialte's reforms in 462 Assembly had more and more frequently used its incrised power to legislate, and the traditional sense of the priority of the law had given way to a sense of that the people in the assembly where the highest power in the state. But in 403 the Athenians returned to the ideas that law, not the people, must be the highest power and the laws must be stable, even if not wholly entrenched. Demosthenes in his speech against Timokrates tells admiringly the story of the Lokrians, who change only one law in 200 years, because they had the marvelous custom that any proposal for a change of a law must be made with a noose round the neck and if the proposal was defeated the noose was drawn tight $(1999,261)$.

Efectivamente, y como se anticipaba, pese a que no es necesario llegar a los extremos de sacralización de la democracia ateniense, el extremo contrario, el de la banalización del control de la calidad, tampoco resulta deseable si se considera que la labor de crear normas jurídicas tiene alguna valía. Por este motivo es preciso determinar y clarificar los mecanismos de control de la calidad de la legislación en los sistemas jurídicos contemporáneos.

Naturalmente, tales mecanismos toman aún más relevancia cuando lo que se va a valorar es la calidad las normas jurídicas producidas por las formas democráticas representativas; al final la rendición de cuentas bien puede ser considerada como la propiedad central de los sistemas representativos (Mattila 2017), dado que: "El gobierno representativo no es un sistema en el que la comunidad se autogobierna, sino un sistema en el que las políticas y las decisiones públicas son sometidas al veredicto del pueblo" (Manin 2005, 236). Si esto es así, la falta de claridad sobre los mecanismos de control de la calidad de la legislación, facilitaría que el trabajo de quiénes son elegidos para representar a la ciudadanía continúen en una zona de discrecionalidad bastante amplia y, por demás, intolerable para la estabilidad política: esta zona de discrecionalidad, bajo la sombrilla de ideas como la de la libertad de configuración del legislador, ${ }^{5}$ ocasiona que se cuelen muchas acciones irreflexivas o, lo que es peor, carentes de transparencia. Si bien se acepta que la "comprensión de la potestad del legisla-

5 "La libertad de configuración de las leyes a cargo del legislador se pone de manifiesto en el hecho consistente en que - con una misma Constitución - pueden emitirse normas secundarias de contenido político completamente diferente e inclusive antagónico" (Silva García y Villeda Ayala 2011). 
dor debe asumir su papel como creador de derecho" (Fuentes-Contreras 2018, 105), las acciones del legislador deben tomar en cuenta tanto la racionalidad como la calidad de los productos que crea: una circunstancia contraria desdibuja, como se ha visto, un concepto nuclear en la democracia representativa, es decir, el de control (Cruz 2003).

En lo que se sigue, la pregunta estará vinculada a ¿cómo entender las ideas de racionalidady de la calidad de la legislación? Pues bien, pese a que definir la noción de racionalidad legislativa no es una tarea sencilla en la medida en la que es un concepto de múltiples dimensiones, si resulta necesaria para la evaluación de los mecanismos de control. En ese marco, autores como Manuel Atienza (1997) se han dado a la tarea de distinguir esas dimensiones de la racionalidad de los productos legislativos, así: a) la racionalidad lingüística, relacionada con la claridad y precisión de los enunciados normativos proferidos por el legislador; b) la racionalidad sistemática, que se vincula con la coherencia que debe existir entre los textos normativos creados por el legislador y su ordenamiento; c) la racionalidad teleológica, que pretende facilitar la coordinación de las acciones de conformidad con los medios seleccionados para el cumplimiento de ciertos propósitos; d) la racionalidad pragmática que evalúa la eficiencia de los medios adoptados para la solución de un determinado problema social, y e) la racionalidad ética que busca la afinidad de las decisiones legislativas con pautas de índole axiológico.

Partiendo de ellas, Aitken coincide en afirmar que la propuesta multidimensional de Atienza es empleable para comprender, también, calidad de la legislación; dado que esta sería aquella que satisface la mayoría, o porque no, todos estos niveles de racionalidad. Sobre este particular comenta la autora:

La calidad de la legislación está dentro de estos dos extremos. El primer extremo se refiere a la sustancia de la ley o su exactitud para representar la decisión política... Esto también se refiere al problema de una decisión política bien estructurada (lo que incluye un análisis de la necesidad de la legislación, de su proporcionalidad y un análisis detallado de la probabilidad de impacto de la propuesta) que sea apropiada para la implementación de la política. Además, el tipo de instrumento legislativo escogido debe ser efectivo en lograr el propósito legislativo. Para cumplir este propósito es necesario que la ley producida sea coherente con ella misma, que sea legalmente armónica (esto es que cumpla con la Constitución y sea compatible con las 
leyes existentes y el sistema legal), que se ajuste a las políticas del gobierno existente, sea eficiente en términos de costos y que se implemente de una manera práctica, transparente y controlable. El segundo extremo está en la forma del texto legal y su inteligibilidad... Esto requiere que el texto legal se caracterice por su claridad, simplicidad y exactitud o falta de ambigüedad, con una estructura lógica que realmente comunique el propósito y los efectos de la ley (Aitken 2013, 5).

En esa dirección, la literatura sobre la materia se ha encargado de efectuar recomendaciones para evitar problemas en la racionalidad lingüística y sistemática de la legislación, bajo el rótulo de técnica legislativa. ${ }^{6}$

Mientras tanto, otra serie de abordajes de la calidad legislativa se han enfocado en el desarrollo de propuestas tendientes a mejorar el nivel teleológico y el nivel pragmático de la legislación, es decir, los niveles de racionalidad que analizan la correspondencia entre fines y medios seleccionados por el legislador para la resolución de un determinado problema social y para su efectiva consecución. Estos últimos abordajes se aproximan al concepto de calidad de la legislación mediante la integración de una serie de principios que deben ser tomados en consideración por el legislador a la hora de crear nuevas normas jurídicas. Entre ellos, estaría, por ejemplo, el trabajo de Wintengs. En efecto, Wintengs hablará de principios tales como: el de alternatividad, el de densidad normativa y el de temporalidad. El principio de alternatividad es entendido como una exigencia para que cualquier limitación externa que el legislador imponga a libertad de la ciudadanía requiera de una justificación, la cual se explica en la existencia de fallas o defectos en la interacción social. Por su parte, el principio de densidad normativa establece un requerimiento adicional a las medidas normativas mediante las que se interpongan sanciones. De acuerdo con él, siempre que la sanción es más grave, mayores deben ser las posibilidades con las que se cuenta para el logro un objetivo social propuesto. En otros términos, cualquier propuesta normativa que pretenda incorporar una sanción tiene un deber de justificación adicional para ser incorporada al ordenamiento jurídico. Por último, se encontraría el prin-

6 A pesar de que "la técnica legislativa se ha centrado en atender y señalar la relevancia de la correcta redacción de las normas, no se circunscribe a este aspecto, se extiende al conjunto de saberes que han de permitir la construcción de un ordenamiento jurídico perfectamente estructurado en relación con la forma y con el contenido" (Sánchez 2012). 
cipio de temporalidad, el cual exige que el legislador considere el componente temporal del sistema normativo: en razón que las reglas jurídicas son asunto de creación humana es preciso hacerles seguimiento para establecer cuáles han sido sus efectos y cuales efectos inesperados pudieron haber surgido (Wintengs 2006).

Definida, entonces, la utilidad del control, las racionalidades y la propia calidad legislativa, el tema subsiguiente sería la institucionalización concreta de los mecanismos de control en un ordenamiento jurídico puntual.

\section{MEGANISMOS DE GONTROL DE LA LEY: ¿CÓMO CONTROLAR LA GALIDAD DE LA LEGISLACIÓN?}

La estructura del Estado se encuentra determinada por la separación de los poderes públicos, de los cuales se espera mutua colaboración, pero también, en igual medida e importancia, mutuos controles y contrapesos. Éste es el esquema al que la tradición constitucional liberal ha denominado como de "frenos y contrapesos", implica que las actuaciones de una rama del poder público que este por fuera de las competencias normativas deben ser frenadas por las otras ramas, mediante el uso de los diversos mecanismos de control existentes en el diseño constitucional. En este marco, las democracias constitucionales contemporáneas han forjado un acervo de mecanismos para controlar la calidad de la legislación.

Efectivamente, la lógica de la imposición de frenos o el ejercicio de mecanismos de control de carácter externo a la actividad legislativa, incluido el control a la calidad de los productos legislativos, es bastante amplia en los sistemas constitucionales contemporáneos.

Ejemplo de ello puede ser visto en el contexto colombiano, donde este conjunto de mecanismos de control se encuentra dispersado a lo largo del texto de la Constitución Política (CP) de 1991. Precisamente, por cuenta de esa atomización, tales mecanismos de control presentan características diversas que, con todo, es posible sistematizar a partir de algunas categorías de análisis comunes: la primera de ellas analiza a estos mecanismos de control a partir de consideraciones sobre el momento o el espacio temporal en el que se activan dichos controles. La segunda, agrupa los mecanismos tomando en consideración la naturaleza del órgano que concretiza o efectúa el control. Por último, estaría la clasificación que se valora a partir del nivel de racionalidad que ellos pretenden evaluar.

Esta obra está bajo una Licencia Creative Commons

Atribución-NoComercial-SinDerivar 4.0 Internacional, IIJ-UNAM.

Boletín Mexicano de Derecho Comparado, núm. 158, mayo-agosto de 2020, pp. 579-618. 


\section{GRÁFICA 1. CLASIFICACIÓN DE LOS MEGANISMOS}

PARA EL CONTROL DE LA CALIDAD LEGISLATIVA

\begin{tabular}{lll} 
& $\begin{array}{l}\text { Espacio temporal de su } \\
\text { realización }\end{array}$ & Previos (ex ante) \\
\cline { 3 - 3 } & & Posteriores (ex post) \\
\cline { 3 - 3 } & Naturaleza del órgano & Horizontal \\
\hline & & \\
\hline
\end{tabular}

En ese orden de ideas, algunos de estos mecanismos de control se activan dentro del trámite de elaboración de la ley y otros finalizado éste. En el caso colombiano se tiene que el procedimiento legislativo prescrito por la CP y por la Ley Orgánica del Reglamento del Congreso - en adelante LORG o Ley 5 de 1992 - estará circunscrito al siguiente esquema:

\section{GRÁFICA 2. ESQUEMA DEL PROCEDIMIENTO LEGISLATIVO de Colombia (Fuentes-Contreras 2018, 257)}

\section{Procedimiento legislativo Constitución colombiana de 1991}

3. Etapa deliberatoria o debates

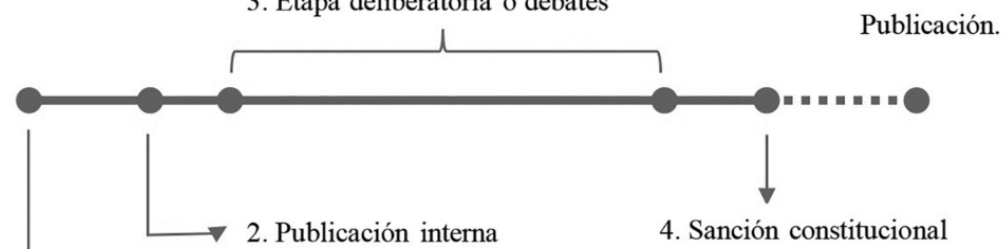

2. Publicación interna 4. Sanción constitucional

1. Presentación del proyecto de ley 
En esa medida, de forma previa a la promulgación de una legislación defectuosa se tendría el mecanismo de objeción presidencial, de los artículos 165 al 167 de la CP, el cual opera antes de la publicación o promulgación de la ley, puntualmente, en el momento de la sanción presidencial o constitucional; buscando por medio de dicha competencia asegurar el cumplimiento de los requisitos materiales (contenido) y formales (procedimentales, forma y competencia) del aún proyecto de ley o su conveniencia política. Desde luego,

...terminada la etapa deliberatoria, siguiendo el artículo 165 de la CP, el proyecto de ley aprobado en los debates será remitido al presidente de la República para la correspondiente valoración y posterior sanción, dentro de los plazos establecidos (artículo 166 de la CP y artículo 198 de la LORC). Debe tenerse en cuenta que la cantidad de artículos que se incluyen en el proyecto de ley será la que determine el espacio de tiempo que tiene el presidente de la República para formular las objeciones, en caso de que haya lugar a las mismas (artículos 166 de la CP y 198 de la LORC).

De ese modo, la valoración que efectuará el presidente, por mandato constitucional, será un control de tipo político y/o constitucional sobre el proyecto aprobado por el Congreso (artículo 200.1 de la CP) y, congruentemente con él, podrá decidir si realizar la sanción constitucional (firma del mismo para darle existencia a la ley) o interponer objeciones al proyecto (Fuentes-Contreras 2018, 271).

Igualmente, estará el control constitucional de las leyes estatutarias: en él, como en el arbitraje que se realiza ante las objeciones presidenciales por inconstitucionalidad, será realizado por la Corte Constitucional. Esto según las prescripciones establecidas en los artículos 153 y 241.8 de la CP, respectivamente.

Asimismo, la Ley 5 de 1992 (artículos 61c y 115), dispone que, en desarrollo del proceso legislativo, diversos actores sociales puedan ser convocados a audiencias públicas, con el propósito de exponer sus puntos de vista sobre un proyecto legislativo. Cada uno de estos mecanismos, en suma, posibilitan que, de forma anterior al proceso de promulgación de la ley, su calidad sea objeto de control.

En contraste, otros mecanismos de control de la calidad legislativa se activan de forma posterior a la promulgación de la ley. Ciertamente, la calidad de la legislación puede ser evaluada ex post en los casos de activación 
del control constitucional rogado o exhortativo por acción (especialmente, artículo 241.4 de la CP) y con ciertos mecanismos de control vertical producidos por agentes de la sociedad civil, los medios de comunicación y por miembros de la academia.

Ahora, así como es posible identificar mecanismos de control que operan ex ante y ex post a la promulgación de la ley y cuya naturaleza puede ser externa, también es posible identificar mecanismos de control que operan al interior de las legislaturas: verbigracia, la conformación de las legislaturas por distintos partidos políticos (artículo 107 de la CP), la estructura bicameral del Congreso (artículo 132 de la CP) y la división de las células legislativas entre comisiones y plenarias durante las etapas deliberatorias (artículo 142 de la CP), funcionan como un mecanismo ex ante de nivel interno. De cualquier modo, las discusiones y divisiones existentes entre los diversos agentes que conforman el órgano legislativo, y que se espera se vean reflejadas en los debates que se realizan, funcionaran con el propósito de contener la promulgación de "mala legislación":

$\mathrm{El}$ aspecto más prominente del proceso legislativo moderno es que él está repleto de un complejo conjunto de obstáculos que los proponentes de una nueva regulación deben superar antes de que un proyecto se convierta en ley. En cada etapa en el proceso legislativo una propuesta puede ser cambiada o detenida, nuevas coaliciones se forman y las oportunidades para los intercambios de favores, conductas estratégicas y deliberación también se presentan. Debido a que quienes controlan estos puntos de estrangulamiento tienen la habilidad de archivar una propuesta, algunos politólogos han acuñado el término vetogates para describir este fenómeno. Estos vetogates emanan de un numero de recursos: algunos son el resultado de provisiones constitucionales, otros de reglas formales adoptadas por el legislativo y otras de reglas o prácticas que son más informales (Eskridge, Frickey y Garrett 2006, 70).

Por último, los mecanismos de control de la calidad legislativa están dirigidos a evaluar distintos grados de racionalidad: así, por ejemplo, la Constitución y las normas que la complementan, como el Estatuto Orgánico del Congreso y disposiciones jurídicas tales como la Ley 819 de 2003, ordenan el cumplimiento de unos parámetros mínimos de calidad de la legislación en los ámbitos lingüístico, sistemático, teleológico, pragmático y ético. En efecto, en relación con la racionalidad lingüística y sistemática, el artículo 158 de la CP prescribe una obligación para que los proyectos 
de ley se refieran a una única materia. ${ }^{7}$ Esta norma pone en cabeza de los presidentes de las comisiones constitucionales permanentes, la obligación de rechazar las propuestas legislativas que contraríen este principio denominado de unidad de materia.

Igualmente, esta disposición establece que: "la ley que sea objeto de reforma parcial se publicará en un solo texto que incorpore las modificaciones aprobadas". Esta prescripción constitucional está dirigida a obtener unos niveles básicos de coordinación normativa que garantice la coherencia interna del sistema jurídico.

Asimismo, el artículo 4 de la CP ordena el deber respetar la racionalidad del sistema jurídico a partir del principio de supremacía constitucional. Este principio está dirigido a todas las autoridades pública incluidos aquellos que crean la ley.

Adicionalmente, el artículo 7 de la Ley 819 de 2003 ordena unos requisitos mínimos de racionalidad pragmática de la legislación: especialmente de las leyes que ordenen gastos o que otorguen beneficios tributarios. Esta norma determina la necesidad que este tipo legislación sean promulgada una vez se haya realizado un estudio de "los costos fiscales de la iniciativa y de las fuentes de ingreso adicional generada para el financiamiento de dicho costo".

Todos estos preceptos asignan una línea de base, aunque poco ambiciosa, a la idea del control de la calidad de la legislación.

De tal modo, la racionalidad lingüística y sistemática, vinculada con el principio de unidad de materia y de publicación en un único texto de las modificaciones a los textos legislativos, puede ser objeto de control por los mecanismos internos de la legislatura. También por mecanismos de control horizontal tales como la objeción presidencial y el control constitucional. Por su parte, lo relacionado con la racionalidad pragmática de la ley es controlado por los mecanismos internos y también por mecanismo externos tales como la objeción presidencial.

Ahora, aunque el sistema legal colombiano hace estas mínimas referencias a ciertos puntos de control de la calidad de la legislación por

7 Ha dicho la Corte Constitucional que "este precepto [artículo 158 de la CP] "se orienta a lograr un mayor grado de racionalización y tecnificación del proceso legislativo en la instancia parlamentaria, garantizando que el trámite de deliberación y aprobación de las leyes se lleve a cabo sobre materias definidas y conocidas desde el mismo surgimiento de la propuesta legislativa" (Sentencia C-392/07). 
medio de los mecanismos horizontales de carácter interno o externo, este ordenamiento guarda un profundo silencio frente a los mecanismos de control vertical. En otras palabras, no existen muchas normas jurídicas que establezcan unos puntos que le faciliten a la sociedad civil, a los medios de comunicación o la academia realizar algún tipo de control de la calidad de la legislación, especialmente después de su promulgación. Lo único que establece la Ley 5 de 1992 es la posibilidad de que la ciudadanía pueda ser citada a audiencias públicas dirigidas por las comisiones legales como la Comisión de los Derechos Humanos, la Comisión de Equidad de la Mujer o las Comisiones Regionales Interparlamentarias con el propósito de desarrollar, informar y divulgar los temas relacionados con estas materias y discutir acerca de los proyectos de ley que sobre estas temáticas cursen en las cámaras legislativas.

Sin embargo, esta normatividad no establece puntos de control ex post o de forma posterior a la promulgación. Pese a que en la actualidad está cursando en el Congreso el proyecto de ley 146/18 en Senado y 255/18 en Cámara que impone una obligación en cabeza de los congresistas de presentar un informe de gestión en audiencias públicas una vez culmine cada legislatura, esta iniciativa tampoco suple este silencio. En efecto, el proyecto establece la obligación de consignar en un informe de gestión lo relacionado con la realización de las funciones jurisdiccionales, electorales, de control político y administrativas de los miembros del Congreso. De igual modo, la iniciativa propone la rendición de cuentas acerca de reuniones con miembros del gobierno y lobistas, viajes, manejo de dinero y sanciones que hayan tenido quienes presentan estos informes durante la legislatura. No obstante, el control de la legislación, de los procesos y de la calidad de los productos legislativos no aparece relacionado como un aspecto que deba ser expuesto al público en los informes de gestión que los congresistas deberán presentar a la ciudadanía.

La siguiente tabla resume los diversos mecanismos de control de la calidad de la legislación en el ordenamiento jurídico colombiano. 


\section{TABla. MEGANismos DE GONTROL DE LA GALIDAD \\ DE LA LEGISLACIÓN EN COLOMBIA}

\begin{tabular}{|c|c|c|c|c|c|c|}
\hline \multicolumn{7}{|c|}{ MECANISMOS DE CONTROL DE CALIDAD LEGISLATIVA } \\
\hline \multicolumn{2}{|c|}{$\begin{array}{l}\text { Momento en el que se } \\
\text { activa el mecanismo de } \\
\text { control }\end{array}$} & \multicolumn{3}{|c|}{$\begin{array}{l}\text { Naturaleza del órgano que } \\
\text { ejerce el mecanismo }\end{array}$} & \multicolumn{2}{|c|}{$\begin{array}{l}\text { Tipo de racionalidad que } \\
\text { controla }\end{array}$} \\
\hline & $\begin{array}{l}\text { Multiplicidad y } \\
\text { diversidad de par- } \\
\text { tidos al interior del } \\
\text { Congreso. } \\
\text { Bicameralismo y di- }\end{array}$ & & $\underset{0}{0}$ & $\begin{array}{l}\text { Multiplicidad y } \\
\text { diversidad de par- } \\
\text { tidos al interior del } \\
\text { Congreso. } \\
\text { Bicameralismo. } \\
\text { División entre cá- } \\
\text { maras y comisiones. }\end{array}$ & 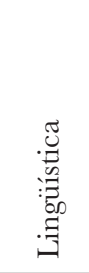 & $\begin{array}{l}\text { Bicameralismo. } \\
\text { División entre cá- } \\
\text { maras y comisiones. }\end{array}$ \\
\hline 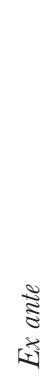 & $\begin{array}{l}\text { iones y plenarias. } \\
\text { Control previo de } \\
\text { constitucionalidad. } \\
\text { Audiencias con ciu- } \\
\text { dadanos y expertos } \\
\text { durante el proceso. } \\
\text { Objeción Presiden- } \\
\text { cial. }\end{array}$ & 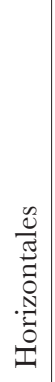 & 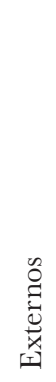 & $\begin{array}{l}\text { Objeción presiden- } \\
\text { cial. } \\
\text { Control consti- } \\
\text { tucional previo y } \\
\text { automático. } \\
\text { Control constitu- } \\
\text { cional posterior y } \\
\text { rogado. }\end{array}$ & 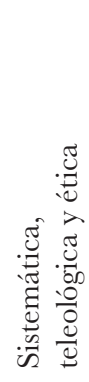 & $\begin{array}{l}\text { Control consti- } \\
\text { tucional previo y } \\
\text { automático. } \\
\text { Control constitucio- } \\
\text { nal por acción. } \\
\text { Objeción presiden- } \\
\text { cial. } \\
\text { Controles verticales } \\
\text { ex ante y ex post. }\end{array}$ \\
\hline 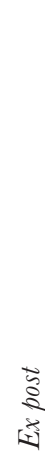 & $\begin{array}{l}\text { Control constitucio- } \\
\text { nal posterior. } \\
\text { Controles verticales } \\
\text { por parte de los } \\
\text { medios de comuni- } \\
\text { cación. } \\
\text { Controles vertica- } \\
\text { les por parte de la } \\
\text { academia. } \\
\text { Control electoral de } \\
\text { la ciudadanía. }\end{array}$ & & 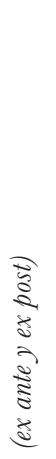 & $\begin{array}{l}\text { Audiencias públicas } \\
\text { durante el proceso. } \\
\text { Denuncias de los } \\
\text { medios de comuni- } \\
\text { cación. } \\
\text { Redes sociales. } \\
\text { Pronunciamientos } \\
\text { desde la academia. }\end{array}$ & 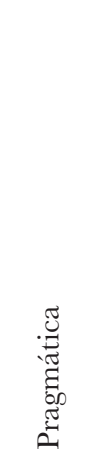 & $\begin{array}{l}\text { Bicameralismo. } \\
\text { División entre } \\
\text { comisiones y ple- } \\
\text { narias. } \\
\text { Concepto previo del } \\
\text { Ministro de Haci- } \\
\text { enda sobre estudio } \\
\text { de impacto fiscal. } \\
\text { Objeción presiden- } \\
\text { cial } \\
\text { Controles verticales } \\
\text { ex ante y ex post. }\end{array}$ \\
\hline
\end{tabular}

Presentado el resumen sobre los mecanismos de control regulados por la CP, se da cabida sobre la pregunta relacionada a la calidad de estos.

Esta obra está bajo una Licencia Creative Commons

Atribución-NoComercial-SinDerivar 4.0 Internacional, IIJ-UNAM.

Boletin Mexicano de Derecho Comparado, núm. 158, mayo-agosto de 2020, pp. 579-618. 


\section{LA GALIDAD ¿ADJETIVO PREDICABLE DE LOS MECANISMOS PARA CONTROLAR LA GALIDAD DE LA LEGISLAGIÓN?}

Tal y como se afirmó en el acápite anterior, los ordenamientos jurídicos contemporáneos disponen de múltiples mecanismos para controlar la calidad de la legislación. Empero, de la existencia de esta variedad de mecanismos no necesariamente se sigue que ellos controlen, simultáneamente, todos los tipos de racionalidad legislativa, ni tampoco que estos controles se realicen de forma adecuada. Este aspecto es especialmente importante frente a los niveles más básicos de racionalidad que parecen estar en un estado de orfandad de control. Orfandad que puede tener como consecuencia la agudización de la idea de la crisis de la representación.

Así, las normas jurídicas terminan siendo descritas y calificadas como inflacionarias, redundantes, segmentadas, confusas, descoordinadas y como predicaciones que sufren de graves padecimientos de hipostenia. Esto es un fenómeno que puede estar directamente relacionado con deficiencias en el tipo de control que se ejerce de los propios niveles básicos de la calidad de la legislación.

En consecuencia, el control horizontal efectuado por los tribunales constitucionales, por ejemplo, se han enfocado en realizar revisiones de los niveles de racionalidad sistemático, teleológico, y hasta ético, de la ley frente a las normas constitucionales. Esta focalización ha implicado un correlativo descuido del control de racionalidad lingüística y de coherencia interna de la propia ley - el nivel más básico de racionalidad de la legislación-. A pesar de lo sorprendente de una afirmación de esta naturaleza, ella no parece ajena a lo que ocurre en otros ordenamientos jurídicos, tal como se ha señalado en el contexto español:

Hay que tener en cuenta que la nuestra es una cultura jurídica en la que la regla o el punto de partida es el no control, y la evolución se identifica con un control contingentado de la ley. Desde luego, entendida la calidad como bondad o acierto, incluso como corrección técnica, el Tribunal Constitucional no considera parte de su ámbito competencial el control de la calidad de las leyes. El Tribunal Constitucional, en efecto, que siempre ha puesto sumo empeño en transmitir la noción de que «su poder» es limitado, ha encontrado en esta esfera, la de la «calidad», un espacio ideal al que confinar su falta de competencia. Su capacidad para controlar a la ley, y de rebote al legislador, 
sería tan contrastablemente limitada que tan pronto se suscita una cuestión de «calidad» se ve obligado a declararse incompetente (Cruz 2003, 152).

\section{Por su parte, la objeción presidencial como medio de control en el} contexto colombiano muestra una notoria preferencia por controlar los niveles de racionalidad sistemática y pragmática. ${ }^{8}$ Este mecanismo también ha dejado más bien huérfana a la idea del control de la calidad de la racionalidad de la legislación en sus niveles básicos. $\mathrm{Al}$ parecer, entonces, el control de la calidad legislativa en estos niveles primarios recae en la academia y otros cuerpos de control vertical, y, a lo sumo, en los mecanismos de control interno. Sólo que ninguno de estos mecanismos se encuentra bien situado para realizarlo de forma efectiva: en primer término, la escasa y lenta incidencia que puede llegar a tener la evaluación realizada desde la academia no muestra una potencia muy fuerte para mejorar la calidad de la legislación. En contraste, los mecanismos de control interno de

8 En este trabajo, por razones de extensión, no hemos realizado un análisis a profundidad del funcionamiento de la figura de la objeción presidencial como medida de control de la calidad de la legislación, debido a que sobrepasada al objetivo propuesto. Debe tenerse en cuenta que para acometer esta tarea en el contexto colombiano es preciso analizar las decisiones proferidas por la Corte Constitucional cuando este tribunal se pronuncia sobre estas objeciones y también las objeciones realizadas por el presidente de la República que han sido acogidas o aceptadas por el Congreso de la República. En estos casos, como la iniciativa legislativa finalmente es archivada, no hay oportunidad para que la Corte Constitucional se pronuncie sobre los motivos que originaron la objeción, ni la aceptación del Congreso de tales objeciones. Sin embargo, una revisión preliminar de las objeciones presidenciales conocidas por la Corte Constitucional en sentencias como la C-625 de 2010 muestra que el presidente de la República suele activar este tipo de control en los casos en los que el órgano legislativo omite incluir el estudio de impacto fiscal de las medidas legislativas propuestas por el órgano parlamentario. En la decisión identificada el Congreso aprobó un proyecto de ley para promover la maternidad responsable mediante la autorización de operaciones de ligaduras de trompas de Falopio con cargo al presupuesto estatal. El presidente objetó el proyecto de ley bajo el argumento de la inexistencia de los estudios de impacto fiscal de la medida propuesta por el Legislativo. Igualmente, la objeción presidencial se activa como mecanismo de control en eventos en los que el Legislativo invade la competencia del presidente para iniciar el trámite legislativo de proyectos de su órbita exclusiva de iniciativa como ocurrió en el caso de la sentencia C-932 de 2009. En este caso específico el Congreso de Colombia amplió la vigencia temporal de una exención tributaria. El presidente objetó el proyecto acusando la carencia de racionalidad sistemática de la iniciativa por trasgredir el artículo 154 de la Constitución. Específicamente, la determinación de la competencia del presidente de la República para iniciar el trámite de leyes sobre "exenciones de impuestos, contribuciones o tasas nacionales".

Esta obra está bajo una Licencia Creative Commons

Atribución-NoComercial-SinDerivar 4.0 Internacional, IIJ-UNAM.

Boletín Mexicano de Derecho Comparado, núm. 158, mayo-agosto de 2020, pp. 579-618. 
las legislaturas no parecen estar funcionando, al menos, cuando se trata de efectuar normas claras y coherentes con el sistema legal.

Así las cosas, estos mecanismos tampoco parecen ser los más idóneos para discutir e incorporar otros niveles de racionalidad más exigentes en los productos legislativos. Ciertamente, y por ejemplo, a partir del uso o no del principio de proporcionalidad en la producción de leyes estatutarias bajo la $\mathrm{CP}$, se ha concluido que estos mecanismos internos no suelen ser rígidos en la necesidad de justificar las elecciones regulatorias del legislador, ni la coordinación entre fines y medios seleccionados a la luz de los principios constitucionales (Rodríguez 2017, 97).

Ahora, respecto a los parámetros mínimos constitucionales y legales exigidos en Colombia en relación con los niveles de racionalidad lingüística, sistemática (de coherencia interna de la ley con el sistema legal) y pragmática, las evidencias serán clarificadas, con algún nivel de detalle, empleando los desarrollos efectuados por la Corte Constitucional en su jurisprudencia. En este orden de ideas, a continuación, se va a realizar una exposición de la forma como ha funcionado el Control Constitucional de estos niveles básicos de racionalidad legislativa, a partir de las sentencias más importantes que ha proferido la Corte Constitucional sobre la materia.

No obstante, antes de ello, debe recordarse que una de las características más particulares del funcionamiento del control constitucional en Colombia está derivada, además de lo ya explicado, de la universalidad de la titularidad de la acción de inconstitucionalidad: dicha titularidad universal, desde la Ley 2 de 1904 e implementada en el acto legislativo 03 de 1910, frente a la Constitución de 1886 y en la CP, con sustento en el artículo 40.6, produce que exista una amplia utilización de este mecanismo de control. En ese marco, dentro de la multiplicidad de alegaciones de las que son susceptibles las normas legales, en algunas ocasiones, la ciudadanía ha acudido para reprochar defectos de calidad de la legislación relacionados con dificultades para comprender los mensajes establecidos en las normas jurídicas proferidas por el órgano legislativo. En esta clase de escenarios, los titulares de la acción de inconstitucionalidad, y el presidente mediante las objeciones, han realizado cargos que esbozan los siguientes problemas de racionalidad básica: 1. Dificultades para comprender el texto legal, derivado de la técnica legislativa, por las inconsistencias en la redacción; 2. Problemas para la interpretación del texto legal en razón a 
afectaciones al principio de unidad de materia; 3. Inconvenientes para la comprensión del precepto legal por la ausencia de correspondencia entre lo dispuesto en el título de la ley y el texto aprobado; 4. Falta de publicación de una nueva ley en un solo texto normativo que determine con claridad las disposiciones vigentes de la anterior legislación.

Empero, en estos escenarios, excepción hecha en lo relacionado con la temática de la ruptura del principio de unidad de materia, el tribunal constitucional colombiano no ha reclamado mayor competencia para pronunciarse estrictamente en relación con esta falta de racionalidad básica, tal como será sintetizado.

\section{Dificultades para comprender el texto legal por problemas de técnica legislativa por inconsistencias en la redacción}

Uno de los primeros abordajes realizados sobre este asunto se hizo en 1999, mediante el salvamento de voto realizado por los entonces magistrados Eduardo Cifuentes Muñoz y Alejandro Martínez Caballero, quiénes reconocen explícitamente los problemas de redacción con los que cuenta el parágrafo del artículo 59 de la Ley 336 de 1996. Sin embargo, los magistrados admiten que

...estos defectos de redacción de la disposición no afectan en sí mismos su constitucionalidad, pues finalmente es posible desentrañar su sentido, aun cuando pueden dificultar notablemente su aplicación, debido a los problemas de interpretación legal que generan, por lo cual nuevamente la Corte insiste en la importancia que tiene una adecuada técnica normativa en los procesos de aprobación de las leyes (Sentencia C-066/99).

Igualmente ocurrió en la sentencia C-479 de 2001, donde la Corte prefirió, pese al reconocimiento de los inconvenientes de redacción, dictar una sentencia condicionada con fines de interpretación.

Para 2004, el accionante expresó una serie de errores de digitación, gramaticales y de redacción de los preceptos demandados que resultaron pasar inadvertidos en su trámite dentro del Congreso. Frente a ello, la Corte dirá que:

...no cabe, de manera general, una pretensión como la expresada, y conforme a la cual sería función del juez constitucional corregir los errores evidentes, 
de digitación, gramaticales o de redacción, o incluso de coherencia interna que se descubran o crean descubrir en las normas. Ciertamente ello puede conducir a dificultades en la aplicación de las normas, pero es allí en donde habrá de producirse la correspondiente respuesta jurídica... tales problemas se desenvuelven en el ámbito de aplicación de la norma y no plantean, per se, un problema de constitucionalidad (Sentencia C-910/04).

Conjuntamente, la Corte terminaría aseverando que no se construyó "un verdadero cargo de inconstitucionalidad y habrá de declararse inhibida para hacer un pronunciamiento en relación con tales disposiciones" (Sentencia C-910/04).

En sentencias como la C-030, de 2006, se mantiene la tesis sobre que no es necesaria la declaratoria de inconstitucionalidad en casos similares; subregla que inclusive, de cierta forma ha sido empleada en ámbitos sancionatorios, en los cuales el tribunal ha dicho que las ambigüedades, derivadas de los conceptos jurídicos indeterminados, afectan el principio de legalidad. Sin embargo, la Corte, en lugar de declarar la inconstitucionalidad, se auto-habilitó para proferir una sentencia condicionada:

...La Corte ha señalado que en virtud de sus competencias puede proferir sentencias de constitucionalidad condicionada si una disposición legal admite varias interpretaciones, "de las cuales algunas violan la Carta pero otras se adecuan a ella, entonces corresponde a la Corte proferir una constitucionalidad condicionada o sentencia interpretativa que establezca cuáles sentidos de la disposición acusada se mantienen dentro del ordenamiento jurídico y cuáles no son legítimos constitucionalmente" (Sentencia C-003/17).9

Con todo, se ha dispuesto que la diferencia entre un control leve o fuerte sobre esta racionalidad lingüística se basa en la contraposición entre el principio de conservación del derecho y el principio de legalidad. Este último ha tenido un peso mayor en los aspectos sancionatorios. Sin embargo, esto no implica que la Corte siempre proceda a la declaración como inconstitucional de esta clase de normas, sino que más bien acude a complementarlas, mediante condicionamientos o adiciones a los enunciados normativos mediante la sentencia del tribunal.

9 Cfr. C-559/99, C-087/00, C-1444/00, C-653/01, C-406/04, C-796/04, C-350/09, C-107/13, C-167/14, C-259/15. 


\section{Problemas para la interpretación del texto legal en razón a afectaciones al principio de unidad de materia}

Las inconsistencias que generan afectaciones al principio de unidad de materia o deficiencias en la sistematización del proyecto también han sido tratadas en diferentes pronunciamientos. En la sentencia C-810 de 2003 la Corte se encarga de estudiar unas objeciones por inconstitucionalidad, pero no se limita a los cargos expuestos por el presidente, sino que extiende su estudio empleando la categoría de la unidad de materia. Puntualmente, el presidente se oponía a ciertos contenidos, sólo que en su estudio el tribunal determinó que estos terminaban afectando la totalidad del proyecto de ley discutido. Por ello,

...no tiene sentido preservar en el ordenamiento elementos de una totalidad, que carecen de contenido propio tomados aisladamente, pues su verdadero significado depende de su lugar en la totalidad normativa de la cual formaban parte. Eso no significa que todos los contenidos normativos de un sistema declarado inexequible estén viciados de inconstitucionalidad, pues pueden ser, tomados aisladamente, o incorporados en otro contexto, perfectamente válidos. Sin embargo, debido a la unidad profunda de sus diferentes componentes normativos, es necesario declarar la inexequibilidad de todo un sistema, si la Corte concluye que sus pilares básicos son contrarios a la Carta (Sentencia C-810/03).

No obstante, hay que aclarar que dicha precisión de la unidad de materia y la racionalidad de los contenidos normativos como una totalidad, había sido ya expuesta en providencias previas como la C-087 de 1998, C-557 de 2000, C-778 de 2001, C-251 de 2002.

La Corte retomó el tema, con alguna importancia, en el 2004 con el salvamento de voto parcial de Rodrigo Uprimny Yepes; en él se puso en tela de juicio la calidad del trámite legislativo y la técnica de producción, al tiempo que criticó la decisión mayoritaria que declaró exequible ${ }^{10}$ una ley aprobatoria de un tratado internacional. Bajo esas ideas, el salvamento

10 La Corte Constitucional de Colombia ha empleado, manteniendo de esta forma lo que hacía con anterioridad a la Constitución de 1991 la Corte Suprema de Justicia, los términos exequible e inexequible en relación con su función de control de constitucionalidad para señalar que una norma es acorde a las disposiciones constitucionales (exequible) o, por el contrario, que la norma revisada está en contra a ellas (inexequible). 
exhibe la línea decisional que ha seguido la Corte sobre dicha temática, esto es: no caer en excesos ritualistas y tomar como criterio orientador al principio de instrumentalidad de las formas. Sólo que el salvamento argumenta que esta línea ha debido tener como límite la protección efectiva de la imparcialidad, la transparencia y la deliberación, así como un control a la ejecución de los diversos controles internos a los procedimientos legislativos (Sentencia C-618/04). Sin embargo, esta postura no ha sido tomada en cuenta para los fallos o decisiones posteriores.

Si se observa en los años subsiguientes, la Corte ha insistido que el control de constitucionalidad que realiza sobre la unidad de materia implica una verificación de conexidades que pueden variar desde lo causal, lo teleológico, lo temático o lo sistemático, después de la determinación del contenido material de la ley concernida (Sentencia C-044, de 2015). En principio y de acuerdo con la jurisprudencia de la Corte, basta, la presencia de uno solo de estos vínculos entre las disposiciones, de manera objetiva y razonable, para evitar la declaración de inconstitucionalidad.

Adicionalmente debe tenerse en cuenta que la revisión de la unidad de materia, no se ha interpretado en sentido estricto, rígido o absoluto, sino que preferiblemente, esta revisión se ha decantado por una ponderación de dicho principio con el principio democrático y el de la libertad de configuración del legislador. ${ }^{11}$ De tal modo, si bien ha dicho la Corte que:

El objetivo de esta garantía constitucional consiste en racionalizar y tecnificar la actividad legislativa, de tal manera que: (i) exista coherencia normativa sistemática reflejada al interior de la Ley con el resto del ordenamiento jurídico; (ii) se impida la inclusión súbita, sorpresiva, inopinada o subrepticia de normas extrañas, aisladas, inconexas y contrarias al objeto de la ley; sobre las cuales no haya existido un verdadero debate; (iii) se consolide la voluntad democrática en el marco de una deliberación pública transparente. Por consiguiente, se restringe la formación de las leyes a un contexto temático determinado, que propende por un diálogo legislativo coherente, informado y productivo y que, como consecuencia de ello; (iv) se garantice la protección de la seguridad jurídica; y (v) se facilite el conocimiento y cumplimiento de

11 Dicha posición fue sostenida de manera reiterada y amplia entre otras sentencias como la C-778 de 2001, C-392 de 2007, C-908 de 2007, C-432 de 2010, C-277 de 2011 , C-133 de 2012, G-721 de 2015, C-015 de 2016, C-204 de 2016, C-353 de 2017. 
la norma por parte de la sociedad y, en particular, de sus destinatarios (Sentencia C-047, de 2018).

Lo cierto es que la amplitud de la categoría, en términos de la Corte Constitucional, y la flexibilidad del control constitucional, no ha favorecido a la construcción de una racionalidad básica y conjunta de la obra legislativa. Muy por el contrario, este fenómeno puede ser analizado como un control contrario a las finalidades correctivas de un mecanismo como el control constitucional. Adicionalmente, estas deficiencias complejizan la vigencia normativa y la interpretación de los preceptos elaborados por el órgano legislativo; todo lo anterior en perjuicio del destinatario final, dado que lo obliga a conocer no sólo la ley, sino la discusión que ha sostenido el tribunal constitucional.

\section{Dificultades para comprender el texto legal por problemas de su título}

En coherencia con el artículo 169 de la CP, que dispone que "El título de las leyes deberá corresponder precisamente a su contenido", la Corte Constitucional ha desarrollado un control derivado de la unidad de materia, diciendo que

Esta disposición constitucional ha permitido a la jurisprudencia constitucional fijar tres premisas acerca del contenido y alcance del precepto, relativas a: (i) la posibilidad de someter el título de las leyes al control de constitucionalidad, a pesar de carecer de un contenido deóntico autónomo; (ii) la función que tiene el título de las leyes en términos de seguridad jurídica y coherencia del trabajo legislativo; y (iii) la vinculación entre la concordancia del título con el texto de la ley y el principio de unidad de materia (Sentencia C-817/11).

Siguiendo esa postura la Corte se ha pronunciado en diversas oportunidades, como en 2006, en donde determinó que esta revisión se configura como un control de "unidad de materia en sentido amplio", al interrelacionar los artículos 158 y 169 de la CP: "De lo anterior se sigue, entonces, que lo que se busca es que exista "unidad" o "correspondencia" entre las disposiciones del cuerpo normativo y, a su vez, entre éstas y el título de la ley, 
el cual debe ofrecer una idea general sobre la materia que dicha ley va a regular" (Sentencia C-82 1/06). ${ }^{12}$ Así,

En cuanto al principio de congruencia, éste busca asegurar que, al realizar la nominación de los textos legislativos, el Congreso de la República se ciña a determinadas pautas que garanticen que dicha labor — orientada a identificar las diferentes leyes del ordenamiento - no obstaculice el cumplimiento de los objetivos que se traza la ley mediante la conducción a yerros o confusiones respecto de su contenido específico. De tal manera, este principio exige del Legislador que al llevar a cabo la tarea de titulación de los textos legislativos, ésta sea realizada de tal manera que permita determinar con simplicidad suficiente su contenido, lo cual ejerce una honda incidencia en el postulado de la publicidad de la ley, pues sin lugar a dudas la errónea o equívoca identificación de ésta puede llevar a su desconocimiento por parte de la ciudadanía y a dificultar su aplicación; lo cual, por esa vía, conduce a la erosión de los objetivos que inspiran la producción legislativa (Sentencia C-908/07).

Pese a que se ha reconocido que el título de una ley carece de valor normativo, si se le observa un valor interpretativo, lo que implica una necesidad de control para que cumpla de manera eficaz las siguientes funciones: a) la conservación de la seguridad jurídica; b) la sistematización del ordenamiento jurídico; c) la publicidad de la ley; d) la influencia en la interpretación del contenido de la ley; y, e. Sirve como uno de los diferentes criterios para establecer el eventual incumplimiento del principio de unidad de materia (Sentencia C-360/16).

Siguiendo ello, ha generado, al interior de su jurisprudencia, ciertas restricciones para los títulos de las leyes; estas son: ${ }^{13}$

- No puede ser discriminatorio, esto es, basarse en criterios que la propia Constitución enuncia como prohibidos para establecer diferenciaciones entre personas, como son la raza, el sexo, el pensamiento político y religioso, etcétera;

- Tampoco pueden sustituir el número y la descripción general del contenido de la jurisprudencia, ya que tales requisitos están esta-

12 En el mismo sentido, ver, por ejemplo: G-908 de 2007, G-230 de 2008.

13 Ver, además: C-821 de 2006, C-152 de 2003, C-1057 de 2005, C - 1040 de 2005, C-400 de 2010, G-393 de 2011. 
blecidos de manera explícita en la Ley Orgánica del Reglamento del Congreso (Ley 5 de 1992), parámetro de constitucionalidad en materia de vicios de procedimiento.

- No puede carecer de relación de conexidad con su contenido, en virtud del principio de unidad de materia que no sólo se predica del contenido normativo, sino también del contenido de la ley, según lo disponen los artículos 169 de la Constitución y 193 de la Ley 5 de 1992, y

- Tampoco debe conceder reconocimientos, privilegios u honores a una persona específica, por ser una materia propia de las leyes de honores (CP, artículo 150-15). (Sentencia C-360/16).

Con todo, dicho control ha sido tratado, igualmente, como un control poco estricto, debido a la mayor movilidad y a la dinámica de los debates y las intervenciones propias que se producen. Esta argumentación permite que la Corte reconozca y maximice, en muchas ocasiones, el margen de valoración del propio legislador, el cual sólo ha quedado restringido, al parecer, en las denominadas leyes interpretativas, debido a que su nominación impide al legislador adelantar cualquier otra labor como agregar, modificar, derogar o sustituir contenidos de la ley que será objeto de interpretación. ${ }^{14}$ Empero, dicha restricción parece inocua si se observa que este tipo de leyes no son productos realmente comunes en el quehacer del Congreso de la República.

\section{Ausencia de publicación de una ley en un solo texto normatioo}

La Corte también ha centrado su interés en el control respecto a la obligación establecida en la última frase del artículo 158 de la $\mathrm{CP},{ }^{15}$ es decir, la necesidad de que una ley que realiza derogaciones a un texto normativo anterior deba compilar las disposiciones vigentes de la anterior disposición en el texto normativo que será vigente; si bien sin una extensión en tratamiento comparado a las anteriores revisiones, la Corte ha aludido a dicho deber vinculando a su función teleológica.

14 Véase sobre ello, entre otras: C-270/93, C-301/93, C-076/07.

15 "La ley que sea objeto de reforma parcial se publicará en un solo texto que incorpore las modificaciones aprobadas".

Esta obra está bajo una Licencia Creative Commons

Atribución-NoComercial-SinDerivar 4.0 Internacional, IIJ-UNAM.

Boletín Mexicano de Derecho Comparado, núm. 158, mayo-agosto de 2020, pp. 579-618. 


\section{En esa perspectiva, señala que el precepto constitucional}

pretendía combatir la dispersión legislativa” (i); propugnar la certeza jurídica (ii); abolir la incertidumbre derivada de la práctica de la derogación tácita (iii)" (Sentencia C-306/96). Sin embargo, desde temprano, la Corte dispuso que dichos objetivos no serían logrados de manera eficaz, sobre todo en lo relacionado con la primera y última función,

...dada la multitud de causas no fácilmente controlables que determinan ambos fenómenos y en vista de que la derogación tácita no fue prohibida por el Constituyente. En otras palabras, sin perjuicio del ámbito propio que delimita el enunciado normativo constitucional, el texto finalmente aprobado, no garantiza objetivamente que se alcancen los loables propósitos que se tuvieron en mente" (Sentencia C-306/96).

Para 1997, mediante sentencia C-076, aclaró el alcance de dicho control, considerando, en primer momento, que la dispersión normativa es un acaecimiento típico en el ordenamiento colombiano y si bien trata de solventarse por el Constituyente mediante el artículo 158 de la CP, la norma constitucional sobre el tema ocasiona que existan una publicación que hace el Ejecutivo en el proceso de creación de la ley, después de la sanción constitucional, y otra para evitar el fenómeno de dispersión; teniendo cada uno de ellos efectos disimiles:

La publicación que exige el artículo 158 de la Constitución, como se ha explicado, busca establecer un parámetro de orden en nuestra legislación, pero no tiene incidencia alguna respecto de la obligatoriedad de la ley en sí misma. Es decir, la falta de publicación que exige esta norma constitucional no hace inoponible la ley que se modifica ni la que introduce las modificaciones, leyes que, independientemente, obligan desde su promulgación, salvo si en su texto se dice otra cosa (Sentencia C-076/97).

Dicha distinción justificó, tal como siguió referenciado en la sentencia C-161 de 1999, que la afectación al artículo 158 de la CP "en nada se afecta su obligatoriedad por que las leyes correspondientes (la que reforma y la reformada) continúan rigiendo hasta cuando el legislador decida derogarlas expresa o tácitamente", lo que llevó, por ejemplo, a inhibirse en la sentencia C-1 186 de 2008, para conocer el cargo de inconstitucionalidad presentado por el accionante; lo cual es otra muestra sustancial de 
un control sin efecto real sobre la calidad legislativa y las racionalidades sistemáticas ampliadas.

Conjunto a lo expuesto, y como fue adelantado, se cuenta con la obligación de la Ley 819 de 2003, la que exige el estudio de impacto fiscal, o de disponibilidad económica para la ejecución de la ley. Sobre ello, en las primeras discusiones, la Corte se limitó a definir la exigencia del requisito en ocasión a la vigencia temporal de la ley, así fue, por ejemplo, en sentencias como C-1113 de 2004, C-500 de 2005, C-729 de 2005, C-072 de 2006, donde no hace explicación en extensos y las características del control.

De cualquier manera, en el último pronunciamiento nombrado la Corte dirá que el requisito de estudio de impacto fiscal será para: a) proyectos de ley que ordenen gasto u otorguen beneficios tributarios; b) deberá satisfacerse durante la totalidad del trámite legislativo, es decir, desde las exposiciones de motivos como en las ponencias y debates, y c) el marco fiscal será un referente vinculante para el análisis del impacto fiscal (Sentencia C-929/06). Estos elementos fueron reiterados en las providencias C-856 y C-929 de 2006, donde se dice que si no existe un marco fiscal al cual deba sujetarse el proyecto de ley a evaluar, entonces el requisito no es exigible. ${ }^{16}$

En ese sentido, el tribunal siguió tasando el requerimiento haciéndolo, por demás, dúctil y casi inexigible en estos casos iniciales, al punto de llegar a señalar, en la C-502 de 2007, y reiterado en la C-1139 de 2008, que la obligación debe ser entendida como un instrumento de racionalización legislativa para el mejoramiento de implementación de políticas públicas,

16 La Corte también señaló que los requisitos son: “1. En la exposición de motivos y en las ponencias de trámite del proyecto debe incluirse los costos fiscales de la iniciativa. 2. En la exposición de motivos y en las ponencias de trámite del proyecto debe incluirse la fuente de ingreso adicional generada para el financiamiento de dicho costo; 3. El Ministerio de Hacienda y Crédito Público, en cualquier tiempo durante el trámite del proyecto en el Congreso de la República, deberá rendir un concepto respecto de la consistencia de los costos fiscales de la iniciativa y la fuente de ingreso adicional generada para el financiamiento de dicho costo. Este informe será publicado en la Gaceta del Congreso. 4. El concepto rendido por el Ministerio de Hacienda y Crédito Público no puede ir en contravía del marco fiscal de mediano plazo. 5. Los proyectos de ley de iniciativa gubernamental, que planteen un gasto adicional o una reducción de ingresos, deberá contener la correspondiente fuente sustitutiva por disminución de gasto o aumentos de ingresos, lo cual deberá ser analizado y aprobado por el Ministerio de Hacienda y Crédito Público" (Sentencia C-373/09). 
pero que no es un modo de coartar el ejercicio de la función legislativa en cabeza del Congreso de la República. Esta postura explica que el estudio sea una obligación dual del gobierno y del Congreso, sólo que el papel protagónico en esta obligación es asumido, precisamente, por el Ejecutivo, liderado por el ministro de Hacienda y Crédito Público, "en cuanto está obligado a ilustrarlo y prevenirlo sobre las implicaciones económicas de la propuesta, sin que el desarrollo de esa labor llegue a representar un veto $\mathrm{u}$ obstáculo en la aprobación del proyecto" (Sentencia C-1 197/08). ${ }^{17}$

Resulta llamativo que, en 2009, la propia Corte hace una manifestación sobre la "constitucionalidad" de la exigencia del estudio al decir que:

aunque hasta la fecha no ha examinado la constitucionalidad del artículo 7 de la Ley 819 de 2003, empero, se ha pronunciado en reiteradas oportunidades sobre las formalidades prescritas por este precepto, con motivo del examen de la constitucionalidad de leyes y de proyectos de ley contra los cuales se planteaba el cargo de desconocer lo señalado en dicha disposición" (Sentencia C-373/09).

Esto dando a entender un cuestionamiento sobre el requerimiento legal del estudio.

Todo lo expuesto termina, en consecuencia, dejando desprovista a la voluntad legislativa de control y la capacidad de garantizar la calidad de la legislación y de su proceso de creación. Escaseando, pese a las modalidades de control establecidas, un ejercicio pensado desde la propia democracia, lo cual bien explica que las políticas públicas no reflejen procesos de planificación y coherencia, y que, en ese contexto desalentador, se termine dando un visto bueno para la contaminación o inflación legislativa. ${ }^{18}$

Si bien per se la cantidad de leyes puede verse como negativa, si se advierte que, como ejercicio político, una mayor cantidad de leyes favorece proporcionalmente a la existencia de leyes con defectuosa calidad o si se

17 Véase, también: C-015A de 2009, G-286 de 2009, C-662 de 2009, C-850 de 2009, C-373 de 2010, C-593 de 2010, C-540 de 2012.

18 "A nivel comparado, Ávila (1990) da cuenta de términos que grafican el incremento de normas; así, refiere a «lluvia de leyes» (Gesetzesflut), «histeria legislativa» (Gesetzgebungshysterie) y «caos legislativo» (Gesetzgebungschaos). Además, habla de «huracán normativo», «incontinencia legislativa» y «aluvión de normas». En esa misma línea, Laporta (2004) refiere a la «proliferación desordenada de leyes», «marea incontenible» y «explosión legislativa»" (Campos 2018). Véase, entre otros: (Mackaay 2018; Šulmane 2011). 
quiere, simplemente, peores leyes. Como bien lo reconoce el profesor Luis Prieto Sanchís, "los efectos de esta inflación legislativa son los mismos que los de la inflación monetaria, la desvalorización” (2012), en otras palabras, la pérdida del valor del derecho en términos de eficacia, certeza, racionalidad y sistematización.

Por demás, analógicamente, también este fenómeno inflacionario o de pérdida de valor se extiende a los mecanismos de control de la calidad legislativa que pese a su existencia y a su cantidad estos suelen ser tan defectuosos, en su aplicación, como la misma ley. Este tipo de problemática, por ende, conduce a la necesidad de pensar propuestas para generar trasformaciones institucionales en los mecanismos de control de la calidad de la legislación, las cuales deben estar vinculadas con el fundamento democrático y representativo que sustenta la creación de la ley por medio de órganos de representación. Ello hace que estas propuestas deban estar en manos de la ciudadanía y en los propios procesos de elección de sus representes como productores de la ley. El ejercicio, entonces, de ese control garantiza la doble participación ciudadana, que se constituye en el fundamento de un Estado democrático de derecho (Díaz 1996).

Por tal motivo, la participación de la ciudadanía y la formulación de rendiciones de cuentas frente al cumplimiento de la labor legislativa dará pie, seguramente, a un conglomerado informado y responsable de los asuntos públicos, mientras valore el impacto de su voto, más allá de la percepción de ser uno entre millones. Al mismo tiempo, esta participación puede conducir a que se obligue a los representantes, y a los demás órganos públicos que ejercen los controles, a tomar en serio la idea de una ley sujeta a calidad para su aplicación y para la (re)construcción constante de la democracia.

\section{GONCLUSIONES}

Con evidencia, y pese a este ser un resultado preliminar de análisis, si se piensa en la deficiencia de los productos legislativos, estos pueden no sólo ser un síntoma, sino la propia causa de la enfermedad de los sistemas democráticos representativos. A su vez, si a esto sumamos la carencia de controles sobre la calidad del producto de la voluntad general, el debilitamiento de dichos sistemas es una consecuencia, por demás, predecible. 
Justamente, la formación de normativas aparentes,${ }^{19}$ más allá de lo ficcional y con excesos, se configura también como un reflejo de insuficiencia en las racionalidades propias de la ley, es decir, la lingüística, la sistemática, la teleológica, la pragmática y la ética.

Si bien es cierto que se aspira un proceso de creación, donde la deliberación y los controles internos favorezcan al perfeccionamiento del producto legislativo como ideal, es sensato pensar, por más visión esperanzadora que se predique, que estos procesos siempre pueden llegar a ser incompletos. Por lo tanto, se necesita un equilibrio y punto de apoyo a la legislación con herramientas que fortalezcan la calidad normativa desde afuera, es decir, desde mecanismos de control externo.

Dichos aspectos han sido examinados, tal como se presentó, por diversos autores, sólo que no siempre en ordenamientos puntuales como el colombiano. ${ }^{20}$ En ese sentido, y habiendo dado cuenta no sólo de la existencia sino del tratamiento de los controles a la calidad de la legislación efectuados ex post por la Corte Constitucional colombiana, se pueden alcanzar las siguientes conclusiones, para el contexto colombiano:

1. Lamentablemente, en Colombia hay una escasa atención por parte de la literatura académica frente a la problemática de la calidad de la ley, y aunque aquella existe, ella se ha organizado en aspectos más de técnica legislativa, sin que se hayan fortalecido y ampliado los estudios jurisprudenciales sobre esta temática.

El robustecimiento de "lo constitucional" y la idea del precedente judicial, hizo que, con la aparición de la CP, se diera un énfasis en la mayor parte de los estudios académicos a definir o cercar lo que piensan las cortes en consonancia con problemas jurídicos o temáticas, y cuando se aborda la ley, su observancia suele ser más referencial en lo correlacional o analítico; con lo cual parece inexistente, en Colombia, una legisprudencia, como forma de estudio del fenómeno jurídico.

2. Quizás es esa ausencia doctrinal la que también explica que la labor creativa de la ley y su calidad se asuma como viciada. Justamente, parece existir una aceptación que el Legislador puede hacerlo "mal", porque

19 En referencia, parcialmente, al uso empleado del texto: (Law y Versteeg 2018).

20 En comparación y sobre propuestas para los sistemas, se sugiere, entre otros: (Caetano y Sarlo 2012; Campuzano 2016; Carrillo 2012; Fernández 2017; Gallegos 2014; Kristan 2014; Marchili 2009; Orta 2017; Raigosa 2008; Rangel y Coutinho 2019; Villota, Pérez y Rengifo 2015). 
existe una Corte Constitucional que redireccione la tarea o complemente la misma. En el ordenamiento jurídico colombiano existe, por tanto, una confianza en el diseño institucional de control ex post, pero no hay verificación profunda sobre hasta dónde puede llegar el mismo e incluso hasta donde ha llegado. Sin embargo, lo observado en este análisis muestra que esta confianza no tiene una adecuada fuente de justificación. Por el contrario, en relación con la calidad de la legislación hay más bien una orfandad en esta clase de control. La Corte Constitucional ha optado por la realización de controles flexibles a la hora de exigir el cumplimiento de los niveles básicos de racionalidad legislativa. En este orden de ideas, a pesar de la existencia de un número importante de decisiones judiciales en las que los ciudadanos solicitan la intervención del tribunal constitucional para mejorar y controlar la racionalidad legislativa, estas intervenciones del tribunal constitucional no han tenido un impacto importante para contribuir a la mejora de los productos legislativos expedidos por el Congreso de Colombia.

3. Estos controles, en primer término, no han contribuido a reducir la discrecionalidad en las posibilidades de adopción de decisiones por parte del órgano legislativo, sino que ha fomentado el realce de la llamada "libertad configurativa". Una libertad configurativa que puede incumplir incluso los objetivos planteados por la propia Constitución. Este problema resulta especialmente grave en la poca precisión de la exigencia de estudios de impacto fiscal de las leyes, que terminan conduciendo a la expedición de normas que, a la postre, no van a contar con recursos para ser implementadas. En segundo lugar, estos controles han contribuido a la generación de un concepto muy amplio de unidad de materia en los textos legislativos. Este fenómeno incide negativamente en la racionalidad sintáctica de la ley y potencia las dificultades interpretativas de los operadores jurídicos que se enfrentan a la tarea de aplicar estas normas. En tercer lugar, la falta de exigencias en relación con la armonización de vigencias legislativas que ha sido permitida por la indiferencia del control ex post de la Corte colombiana para hacer exigible los mandatos constitucionales sobre el tema, es un factor que continúa agudizando los problemas de calidad de la legislación por el impacto directo en la racionalidad sistémica del ordenamiento colombiano.

4. De allí, que sea importante avanzar en una serie de propuestas que generen trasformaciones reales en el contexto colombiano en relación con

Esta obra está bajo una Licencia Creative Commons

Atribución-NoComercial-SinDerivar 4.0 Internacional, IIJ-UNAM.

Boletín Mexicano de Derecho Comparado, núm. 158, mayo-agosto de 2020, pp. 579-618. 
esta temática. Estos avances requieren de una aproximación crítica al funcionamiento de los controles ex ante y ex post a la calidad de los productos legislativos. Unos controles que como se ha mostrado en esta aproximación preliminar han dejado más bien huérfana a la exigencia de calidad en los niveles básicos de racionalidad legislativa. Una forma de evitar esta orfandad en los controles puede desarrollarse a partir de medidas sencillas y fácilmente aplicables por el órgano legislativo colombiano, tales como la compilación y sistematización de las decisiones de la Corte Constitucional para el control constitucional de la racionalidad de los productos legislativos. Esta clase de sistematización permitirá una identificación y clarificación de los controles jurídicos al producto legislativo, además de ser un factor que puede contribuir a la generación de diálogos que materialicen el principio de colaboración armónica entre los poderes públicos. En efecto, a partir de la identificación de algunos errores o defectos recurrentes se puede generar un efecto virtuoso de control ex ante de futuros productos legislativos. Este tipo de mecanismo de chequeo previo debe estar en cabeza de quienes se encargan de diseñar los proyectos que se convertirán en futuras leyes de la República.

Además, este tipo de revisiones podrían estar acompañadas por propuestas que han sido exitosas en derecho comparado, tales como: la implementación y mejora de comisiones o dependencias dentro del Poder Legislativo con el fin de fortalecer la calidad del producto legislativo; la generación y adopción de disposiciones legales o guías para la redacción de las leyes; la publicación de los listados de autores y redactores de los proyectos legales y de sus correspondientes modificaciones; entre otros ( $c f$. Carrillo 2012, 30 y 31).

Esta sistematización que detecte el mapa de los principales problemas en la calidad de la legislación y la forma como las subreglas de la Corte Constitucional han contribuido o no a su solución puede contribuir a generar un ambiente de diálogo interinstitucional y de colaboración armónica entre los poderes públicos colombianos. Un diálogo que permita que la Corte Constitucional refine sus líneas y parámetros de control para exigir mayor una calidad y racionalidad legislativa y que a su vez retroalimente el trabajo de los hacedores de normas jurídicas. Esto evitaría una intervención innecesaria y que, por demás, pone en riesgo el equilibrio institucional y el principio constitucional de la división del poder público, consagrado en el artículo 113 constitucional, de la Corte Constitucional 
mediante sentencias que adicionen, integren, modulen, las disposiciones del Congreso y que puedan ser vistas como formas de usurpación de las competencias previstas en la ingeniería constitucional, mientras se refuerza una visión de una democracia representativa carente de actividad y confiada en los órganos jurisdiccionales carentes de elección democrática directa.

Al final, si se considera que "no es posible ningún discurso práctico desprovisto de una pretensión de corrección” (García Figueroa 2015, 325), ello supone que se abogue por una razón práctica legislativa desde los controles y que favorezca las exigencias de legislación con calidad para el rejuvenecimiento de una real democracia representativa.

5. Por último, además de los controles horizontales, los problemas de calidad de la legislación deben abordarse, mediante de la adopción de mecanismos de rendición de cuentas ante la ciudadanía de los productos legislativos y de su impacto en el orden jurídico y social. En definitiva, los controles jurídicos son insuficientes para la solución de los problemas de calidad de la ley. Por ello se requieren mecanismos de control social y de rendición de cuentas que simultáneamente se extiendan, como una contribución al ejercicio de renovación de la autorización electoral que hace la ciudadanía por medio de los procesos democráticos.

\section{BIBLIOGRAFÍA}

Aitken, Victoria E. 2013. "An exposition of legislative quality and its relevance for effective development". ProLaw Student Fournal (2): 1-43.

Atienza, Manuel. 1997. Contribución para una teoría de la legislación. Madrid. Civitas.

AtienZA, Manuel. 2005. "Reasoning and Legislation". Luc J. Wintgens (ed.). The Theory and Practice of Legislation. Aldershot. Ashgate, 297-317.

BAR-SIMAN-TOV, Ittai. 2019. "El resurgimiento global de la Legisprudencia: una aproximación comparada al papel de la legislación en la educación e investigación jurídica". Oliver-Lalana, A. Daniel (ed.). La legislación en serio. Estudios sobre derecho y legisprudencia. Valencia. Tirant Lo Blanch, 522-558.

Gaetano, Gerardo y SARLO, Óscar (coords.). 2010. Técnica legislativa. Teoría, métodos y aspectos político-institucionales. Montevideo. PNUD. 
Campos Ramos, Milagros. 2018. "Más normas, menos seguridad: el problema de la seguridad jurídica en todo proceso de reforma". Vox Furis 1 (35): 117-125. https://wwreaulavirtualusmp.pe/ojs/index.php/VJ/ar ticle/view/1282/pdf9

Campuzano Montoya, Irma. 2016. Técnica legislativa. México.

Carrillo García, Yoel. 2012. "Calidad de las leyes: algunos puntos críticos". Ratio Furis, 7 (14): 21-51.

Celemín Caicedo, Yenny Andrea. 2016. "La importancia de los mecanismos de control del cumplimiento del trámite legislativo para el derecho constitucional". Gregorio Eljach Pacheco et al. (coords.). Procesos legislativos y ordenamiento constitucional: abordajes teóricos. Bogotá, D.C. Senado de la República de Colombia, 72-91. https://wwreacademia. edu/37234085/Yenny_Andrea_Celem\%C3\%ADn_Caicedo_La_influencia_ de_la_jurisprudencia_de_la_Corte_Constitucional_en_el_proceso_legislativo_en

Centenera SÁnchez-Seco, Fernando. 2012. "La crisis de la ley en Luigi Ferrajoli: algunas consideraciones desde la teoría de la legislación". Cuadernos Electrónicos de Filosofia del Derecho 26: 283-309. https://ojs.uv.es/ index.php/CEFD/article/view/1827

Centenera SÁnchez-Seco, Fernando. 2015. "La claridad legislativa en el pensmaiento de Lon L. Fuller: un análisis desde la teoría de la legislación". Anales de Derecho 33 (1). https://revistas.um.es/analesderecho/ article/view/188801

Centenera SÁnchez-Seco, Fernando. 2016. "La formación en legística: aún una asignatura pendiente". Anuario da Facultade de Dereito da Universidade da Coruña 20: 283-309. https://ruc.udc.es/dspace/bitstream/handle/2183/21749/AD_2016_20_art_13.pdf? sequence $=3$ EisAllowed $=y$

CORMACAIN, Ronan. 2017. "Legislation, legislative drafting and the rule of law". The Theory and Practice of Legislation 2 (5): 115-135. https://doi.or g/10.1080/20508840.2017.1394045

CRIADO, Marcos. 2018. "Sobre el concepto de representación política". Revista de Derecho del Estado 28: 77-114. https://revistas.uexternado.edu.co/ index.php/derest/article/view/3180

Gruz Villalón, Pedro. 2003. "Control de la calidad de la ley y calidad del control de la ley". Derecho Privado y Constitución 17: 147-168. https:// dialnet.unirioja.es $/$ servlet/articulo? codigo $=835575$

Cabo Martín, Carlos de. 2000. Sobre el concepto de la ley. Madrid. Trotta. 
DíAz, Elías. 1996. "Democracia: Doble participación". Contrastes. Revista Internacional de Filosofia [Suplemento I]: 197-221. http://wrwre.uma.es/contrastes/pdfs/SUPL1996/ContrastesM96-11.pdf

Elster, Jon. 1999. "Accountability in atenian democracy". Adam Przeworski y Susan C. STOKes, Bernard Manin (eds.). Democracy, Accountability and Representation. Cambridge. Cambridge University Press, 253-278.

ESkrIDGe, William N., Frickey, Philip P. y GARRetT, Elizabeth. 2006. Legislation and Statutory Interpretation. New York. Foundation Press.

Fernández Blanco, Carolina. 2017. Un aporte jurídico a los debates sobre instituciones y desarrollo. Aproximación desde problemáticas compartidas por los países de América Latina. Tesis doctoral. Girona. Universitat de Girona. http://hdl.handle.net/10803/482041

FLORES, Imer B. 2005. "The quest for legisprudence: Constitutionalism v. Legalism". Luc J. Wintgens (ed.). The Theory and Practice of Legislation. Aldershot. Ashgate, 26-52.

FUENTES-CONTRERAS, Édgar Hernán. 2018. Legislación en sentido material. Bogotá, D.C. Ibáñez y otro.

Gallegos Moreno, Martha. 2014. Elaboración de leyes. Proyectos e iniciativas legislativas. Zacatecas. Instituto de Investigaciones Legislativas.

García FigueroA, Alfonso. 2015. "Legislación y neoconstitucionalismo". Anales de la Cátedra Francisco Suárez 49: 311-332. https://revistaseug. ugr.es/index.php/acfs/article/view/3287

Gascón Abellán, Marina Felicia. 2006. "Calidad de las normas y técnica normativa". Revista Española de la Función Consultiva 6: 41-96. http:// portales.gva.es/cjccv/pdfs/pub/refc-n6.pdf

JARAMILlO JASsiR, Mauricio. 2018. "La vigencia de Satori en las inacabadas definiciones de democracia y régimen democrático". Desafios 1 (30): 359-366. https://revistas.urosario.edu.co/index.php/desafios/article/ view/5943

KARPEN, Ulrich. 2013. "Comparative Law: Perspectives of Legislation". Anuario Iberoamericano de Fusticia Constitucional 17: 141-185. https://recyt. fecyt.es/index.php/AIfC/article/view/40777

KRISTAN, Andrej. 2013. "Cómo justificar una (no) intervención legislativa? Los elementos clave para un discurso legisprudencial”. GRÁNDEZ, Pedro y MORALES, Félix (eds.). La argumentación jurídica en el Estado constitucional, eds. Lima. Palestra, 479-490.

Esta obra está bajo una Licencia Creative Commons

Atribución-NoComercial-SinDerivar 4.0 Internacional, IIJ-UNAM.

Boletín Mexicano de Derecho Comparado, núm. 158, mayo-agosto de 2020, pp. 579-618. 
LAPORTA, Francisco J. 1999. "Materiales para una reflexión sobre racionalidad y crisis de la ley". Doxa 22: 321-330. http://dx.doi.org/10.14198/ DOXA1999.22.14

Law, David S. y Versteeg, Mila. 2018. Constituciones Aparentes. Bogotá, D.C. Universidad Externado de Colombia.

MACKAAY, Ejan. 2018. "L’inflation normative". Lex electronica (23): 30-51. https://wrere.lex-electronica.org/en/articles/volume-23/linflation-normative/

Manin, Bernard. 2005. Los principios del gobierno representativo. Barcelona. Gedisa.

MARChILI, Luis Alberto. 2009. Como legislar con sabiduría y elocuencia. Buenos Aires. Dunken.

Marcilla Córdoba, Gema. 2000. "Sobre la necesidad de una nueva ciencia de la legislación”. Miguel Carbonell y Susana Thalía Pedroza de la Llave (coords.). Elementos de técnica legislativa. México. UNAM, 92115. https://archivos.juridicas.unam.mx/wrew/bju/libros/1/21/tc.pdf

Mattila, Maija. 2017. From Representative Democracy to Democratic Representation. Tampere. University of Tampere. https://trepo.tuni.fi/hand le/10024/102309

Niemivuo, Matti. 2010. Legislative drafting process. Main issues and some examples. Strasbourg. European Commission for Democracy Through Law.

ORTA Flores, Sara Berenice. 2017. Las violaciones al procedimiento legislativo mexicano: estudio de causas y efectos a través del control abstracto de constitucionalidad. Ciudad México. Suprema Corte de Justicia de la Nación.

PINEDA Garfías, Rodrigo. 2009. "Teoría de la legislacion. Algunos planteamientos generales". Nomos 3: 137-156. https://wwre.academia. edu/24708057/Teor\%C3\%ADa_de_la_legislaci\%C3\%B3n._Algunos_planteamientos_generales

PRIETO Sanchís, Luis. 2012. "Política legislativa, técnica legislativa, y codificación en los albores del siglo XXI". Anuario de historia del derecho español 82: 387-412. https://wrere.boe.es/publicaciones/anuarios_derecho/articulo. php? id=ANU-H-2012-10038700412

RAIGOSA Sotelo, Luis. 2008. ¿Cómo hacer una iniciativa de ley?. México. Senado de la República.

Rangel Alvarez dos Santos, Fernando y Carlos André Coutinho Teles. 2017. "O Estudo De Impacto Legislativo - Possibilidades E Controvérsias". Alexandre Walmott Borges y Paulo Roberto Barbosa Ramos (coords.). Teoría constitucional. Florianópolis. CONPEDI, 44-59. 
RODRÍGUEz MARTíNEZ, Christian. 2017. El principio de proporcionalidad por el legislador. Santa Marta. Universidad del Magdalena.

Rubio CARRACEDO, José. 2000. “CGansancio de la democracia o acomodo de los políticos?”. Claves de Razón Práctica 105: 76-82.

Rubio Llorente, Francisco. 2006. "El papel del Consejo de Estado en el control de la calidad técnica de las normas". Revista Española de la Función Consultiva 6: 27-41. http://portales.gva.es/cjcco/pdfs/pub/refc-n6.pdf SÁnchez Gómez, Elia. 2012. "Técnica Legislativa". MORA-DONATTO, Cecilia y SÁNCHez Gómez, Elia (eds.). Teoría de la legislación y técnica legislativa (Una forma nueva de entender y ejercer la función legislativa). México. UNAM y otro, 71-127.

Silva García, Fernando y Villeda Ayala, Alfredo. 2011. "Libertad de configuración legislativa e irretroactividad de las leyes". Revista del Instituto de la Fudicatura Federal 31, 177-210. https://revistas-colaboracion.juridi cas.unam.mx/index.php/judicatura/article/view/31970

Šulmane, Dace. 2011. "Legislative Inflation - An analysis of the Phenomenon in Contemporary Legal Discourse". Baltic Fournal of Law \& Politics 2 (4): 78-101. https://doi.org/10.2478/v10076-011-0013-4

Tudela ARANDA, José. 2000-2001. "Calidad y renovación del concepto de ley". Anuario jurídico de La Rioja 6-7: 103-153. https://publicaciones.uni rioja.es/ojs/index.php/ajr/article/view/776/672

Vallejo, César. 2018. "Mínimos democrativos para un Congreso representativo". PAdrón PARdo, Floralba y CORREa HenaO, Magdalena (eds.). ¿El Estado constitucional en jaque?,. Bogotá, D.C. Universidad Externado de Colombia, 61-89.

Villota Gerna, Marco Antonio, Pérez Paredes, Yon Javier y RenGIFO ARÉvalo, Groffer Joy. 2015. La Ley y la Técnica Legislativa. Lima. Congreso de la República del Perú.

Van Reybrouck, David. 2017. Contra las elecciones. Cómo salvar la democracia. Madrid. Taurus.

Wintengs, Luc J. 2006. "Legisprudence as a New Theory of Legislation". Ratio Furis 1 (19): 1-25. https://wrere.academia.edu/1459886/Legis pru dence_as_a_New_Theory_of_Legislation. 